\title{
Rottlerin Inhibits Lonicera japonica-Induced Photokilling in Human Lung Cancer Cells through Cytoskeleton-Related Signaling Cascade
}

\author{
Bang-Jau You, ${ }^{1}$ Yang-Chang Wu, ${ }^{2}$ Bo-Ying Bao, ${ }^{3}$ Chi-Yu Wu, ${ }^{4}$ Ya-Win Yang, ${ }^{3}$ Yu-Hao Chang, ${ }^{3}$ \\ and Hong-Zin Lee ${ }^{3}$ \\ ${ }^{1}$ School of Chinese Medicine Resources, China Medical University, 91, Hsueh-Shih Road, Taichung 40402, Taiwan \\ ${ }^{2}$ Graduate Institute of Integrated Medicine, China Medical University, 91, Hsueh-Shih Road, Taichung 40402, Taiwan \\ ${ }^{3}$ School of Pharmacy, China Medical University, 91, Hsueh-Shih Road, Taichung 40402, Taiwan \\ ${ }^{4}$ Department of Internal Medicine, Chang-Hua Hospital, 80, Chung-Cheng Road Sec. 2, Puhsin 51341, Chang-Hua, Taiwan
}

Correspondence should be addressed to Hong-Zin Lee, hong@mail.cmu.edu.tw

Received 23 September 2010; Revised 11 December 2010; Accepted 5 January 2011

Copyright (C) 2011 Bang-Jau You et al. This is an open access article distributed under the Creative Commons Attribution License, which permits unrestricted use, distribution, and reproduction in any medium, provided the original work is properly cited.

\begin{abstract}
This study demonstrated that many apoptotic signaling pathways, such as Rho family, PKC family, MAP kinase family, and mitochondria-mediated apoptotic pathway, were triggered by Lonicera japonica extracts and irradiation in $\mathrm{CH} 27 \mathrm{cells}$. Rottlerin, a $\mathrm{PKC} \delta$-selective inhibitor, reversed the photoactivated Lonicera japonica extract-induced decrease in PKC $\delta$ protein expression and change in cell morphology in this study. In addition, rottlerin inhibited the photoactivated Lonicera japonica-induced decrease in protein expression of Ras, ERK, p38, $\mathrm{PKC} \alpha$, and $\mathrm{PKC} \varepsilon$, which are the kinases of prosurvival signaling pathway. We also demonstrated that pretreatment with rottlerin prevented actin microfilaments and microtubules from damage during the photoactivated Lonicera japonica-induced $\mathrm{CH} 27$ cell death. Furthermore, the promotion of the cytoskeleton-related signaling cascade following rottlerin by upregulation of cytoskeleton-related mediators (p38, HSP27, FAK, paxillin, and tubulin) and molecules of downstream of F-actin (mitochondria-mediated apoptosis pathway) reduces $\mathrm{CH} 27$ cell death, indicating that cytoskeleton is the potential target in the photoactivated Lonicera japonica extract-induced photokilling of $\mathrm{CH} 27$ cells.
\end{abstract}

\section{Introduction}

Photodynamic therapy is becoming widely accepted as a potential treatment for many forms of cancer and based on the administration of a tumor-localizing photosensitizing agent which is activated by light of appropriate wavelength. It has been demonstrated that photodynamic therapy is a treatment option for lung cancer that involves the administration of a photosensitizing agent and fiberoptic bronchoscope, which was used to deliver of light to tumor tissue that has retained the agent $[1,2]$. Our previous study demonstrated that Lonicera japonica extracts exhibited significant photocytotoxicity in human lung squamous carcinoma $\mathrm{CH} 27$ cells at a concentration range of $50-150 \mu \mathrm{g} / \mathrm{mL}$, with $0.4-$ $1.2 \mathrm{~J} / \mathrm{cm}^{2}$ light dose [3]. The p38-associated pathway was demonstrated to be involved in the photoactivated Lonicera japonica extract-induced $\mathrm{CH} 27$ cell apoptosis [3].

Apoptosis is a major form of cell death, which involves many factors and signal transduction molecules. The severe morphological changes in apoptotic cells were demonstrated that apoptosis has dramatic implications on the cytoskeleton. Several reports suggested that the actin cytoskeleton plays an important role in the early stage of inducing of apoptosis $[4,5]$. Many investigators also indicated that mitochondrial activity as reflected by mitochondria membrane potential should have a significant bearing for F-actin assembly $[6,7]$. Therefore, this study examined the relationship between the redistribution of F-actin and mitochondrial function in the photoactivated Lonicera japonica extract-induced $\mathrm{CH} 27$ cell death.

Rottlerin, also called mallotoxin, is a natural compound isolated from the tree Mallotus philippinensis (the monkeyfaced tree). Many studies have employed rottlerin as a protein kinase $\mathrm{C} \delta$-selective inhibitor and mitochondrial uncoupler [8-11]. Therefore, rottlerin has both proapoptotic and antiapoptotic effects, which are consistent with an antiapoptotic effect of PKC $\delta$ and rottlerin acting via uncoupling mitochondria, because classical mitochondrial uncouplers 
can promote apoptosis [9-11]. In this study, we found that rottlerin blocked the photoactivated Lonicera japonica extract-induced $\mathrm{CH} 27$ cell death. Therefore, we used rottlerin to investigate the mechanisms of photoactivated Lonicera japonica extract-induced $\mathrm{CH} 27$ cell death.

We examined the effect of Lonicera japonica extracts with light on cytotoxicity in several tumor cell lines. A series of photocytotoxic screen tests showed that Lonicera japonica extracts with light exhibited significant cytotoxicity in lung carcinoma cells ( $\mathrm{CH} 27$ and H460), skin cancer cells (M21), and oral cancer cells (HSC-3). The overall objective of the present study is to further explore the integrated mechanism of photoactivated Lonicera japonica-induced human lung carcinoma $\mathrm{CH} 27$ cell apoptosis. We also used rottlerin as a tool of research to demonstrate that cytoskeleton is the potential target in photoactivated Lonicera japonica extractinduced $\mathrm{CH} 27$ cell apoptosis.

\section{Methods}

2.1. Materials. The voucher specimens (Lonicera japonica: CMU LJ 0614) were deposited in School of Chinese Medicine Resources, China Medical University, Taichung, Taiwan. Antipain, aprotinin, dithiothreitol (DTT), ethyleneglycol-bis $(\beta$ aminoethyl ether)-N, $\mathrm{N}^{\mathrm{N}^{\prime}}, \mathrm{N}^{\prime}$-tetraacetic acid (EGTA), leupeptin, pepstatin, phenylmethylsulfonyl fluoride, rottlerin (1-[6-[(3-acetyl-2,4,6-trihydroxy-5-methylphenyl)methyl]5,7-dihydroxy-2,2-dimethyl-2H-1-benzopyran-8-yl]-3-phenyl-2-propen-1-one), Tris, and TRITC (tetramethylrhodamine isothiocyanate)-conjugated phalloidin were purchased from Sigma Chemical Company (St. Louis, MO, USA). FAK, $\beta$-actin, and HSP27 antibodies were from Sigma Chemical Company. Ras, Rho, Cdc42, ERK, JNK, p38, PKC $\alpha$, PKC $\delta$, and $\mathrm{PKC} \varepsilon$ antibodies were purchased from BD Biosciences (San Diego, CA, USA). Tubulin and paxillin antibodies were purchased from Calbiochem (San Diego, CA, USA).

2.2. Preparation of Lonicera japonica. The air-dried plants of Lonicera japonica $(200 \mathrm{~g})$ were soaked three times with $1 \mathrm{~L}$ of $95 \%$ ethanol at room temperature for 3 days. The extracts were filtered. The filtrates were collected and then concentrated under reduced pressure at $40^{\circ} \mathrm{C}$. The yield of dry extract of Lonicera japonica was about 11\%.

2.3. Cell Culture. $\mathrm{CH} 27$ cells were grown in monolayer culture in Dulbecco's modified Eagle's medium (DMEM; Gibco BRL, Rockville, MD, USA) containing 10\% FBS (HyClone, Logan, UT, USA), $100 \mathrm{U} / \mathrm{mL}$ penicillin and $100 \mu \mathrm{g} / \mathrm{mL}$ streptomycin (Gibco BRL), and $2 \mathrm{mM}$ glutamine (Merck, Darmstadt, Germany) at $37^{\circ} \mathrm{C}$ in a humidified atmosphere comprised of $95 \%$ air and $5 \% \mathrm{CO}_{2}$. When $\mathrm{CH} 27$ cells were treated with Lonicera japonica extracts, the culture medium containing $1 \%$ FBS was used.

2.4. Light Source. The irradiation source was a set of fluorescent lamp (20 W, China Electric MFG. Corporation, Taiwan) located at a made-to-measure box. The wavelength of fluorescence lamp is in the range of $400-700 \mathrm{~nm}$. The intensity of light was measured as Lux, a system international illumination measure. Lux was inverted to light dose $\left(\mathrm{J} / \mathrm{cm}^{2}\right)$. The cells were irradiated at $40 \mathrm{~W}$ for $30 \mathrm{~min}$ that correspond to $0.8 \mathrm{~J} / \mathrm{cm}^{2}$ light dose.

2.5. Protein Preparation. Cells were seeded at a density of 1.7 $\times 10^{6}$ cells onto $10-\mathrm{cm}$ dish $48 \mathrm{~h}$ before being treated with drugs. CH27 cells were incubated with $100 \mu \mathrm{g} / \mathrm{mL}$ Lonicera japonica extracts for $4 \mathrm{~h}$ and then irradiated with $0.8 \mathrm{~J} / \mathrm{cm}^{2}$ fluence dose. After irradiation, adherent and floating cells were collected at the indicated time intervals and washed twice in ice-cold phosphate-buffered saline (PBS). Cell pellets were resuspended in lysis buffer $(50 \mathrm{mM}$ Tris- $\mathrm{HCl}$, $\mathrm{pH} 7.5,150 \mathrm{mM} \mathrm{NaCl}, 1 \%$ Nonidet P-40, $0.25 \%$ sodium deoxycholate, $1 \mathrm{mM}$ EGTA, $1 \mathrm{mM}$ DTT, $1 \mathrm{mM}$ phenylmethylsulfonyl fluoride, $1 \mathrm{mM}$ sodium orthovanadate, $1 \mathrm{mM}$ sodium fluoride, $5 \mu \mathrm{g} / \mathrm{mL}$ aprotinin, $5 \mu \mathrm{g} / \mathrm{mL}$ leupeptin, and $5 \mu \mathrm{g} / \mathrm{mL}$ antipain) for $30 \mathrm{~min}$. Lysates were clarified by centrifugation at $13,000 \mathrm{rpm}$ for $30 \mathrm{~min}$ at $4{ }^{\circ} \mathrm{C}$ and the resulting supernatant was collected, aliquoted, and stored at $-80^{\circ} \mathrm{C}$ until assay. The protein concentrations were estimated with the Bradford method.

2.6. Western Blot Analysis. Samples were separated by various indicated concentrations of sodium dodecyl sulfatepolyacrylamide gel electrophoresis (SDS-PAGE; Bio-Rad, Hercules, CA, USA). The SDS-separated proteins were equilibrated in transfer buffer $(50 \mathrm{mM}$ Tris- $\mathrm{HCl}, \mathrm{pH} 9.0-$ 9.4, $40 \mathrm{mM}$ glycine, $0.375 \%$ SDS and $20 \%$ methanol) and electrotransferred to Immobilon-P Transfer Membranes (Millipore Corporation, Bedford, MA, USA). The blot was blocked with a solution containing $5 \%$ nonfat dry milk in Tris-buffered saline (10 mM Tris- $\mathrm{HCl}$ and $150 \mathrm{mM} \mathrm{NaCl}$ ) with $0.05 \%$ Tween 20 (TBST) for $1 \mathrm{~h}$, washed, and incubated with various indicated antibodies. Secondary antibody consisted of a $1: 20,000$ dilution of horseradish peroxidase (HRP)-conjugated goat antimouse IgG (for PKC $\alpha$, Ras, Rho, Cdc42, ERK, JNK, p38, tubulin, and paxillin) or antirabbit IgG (for PKC $\delta, \mathrm{PKC} \varepsilon, \mathrm{FAK}$, and HSP27). The enhanced chemiluminescent (NEN Life Science Products, Boston, MA, USA) detection system was used for immunoblot protein detection.

2.7. Mitochondrial Reductase Activity. Cells were seeded at a density of $1 \times 10^{5}$ cells per well onto a 12 -well plate $48 \mathrm{~h}$ before being treated with drugs. The cells were incubated with $0.1 \%$ ethanol or $100 \mu \mathrm{g} / \mathrm{mL}$ Lonicera japonica extracts for $4 \mathrm{~h}$ and then irradiated with $0.8 \mathrm{~J} / \mathrm{cm}^{2}$ fluence dose. After irradiation, the cells were washed with PBS. Cellular mitochondrial reductase activity of live $\mathrm{CH} 27$ cells was determined by measuring the reduction of 3-(4,5-dimethylthiazol-2-yl)-2,5-diphenyltetrazolium bromide (MTT). At each end point, the treatment medium was replaced with fresh serum-free medium containing $2.4 \times 10^{-4} \mathrm{M}$ MTT at $\mathrm{pH}$ 7.4. Cells were incubated with MTT medium for $1 \mathrm{~h}$ at $37^{\circ} \mathrm{C}$. After solubilization in dimethylsulfoxide, absorbance was measured at $550 \mathrm{~nm}$. 
2.8. Morphological Investigation. Cells were seeded at a density of $1 \times 10^{5}$ cells per well onto 12 -well plate $48 \mathrm{~h}$ before being treated with drugs. The cells were incubated with $0.1 \%$ ethanol or $100 \mu \mathrm{g} / \mathrm{mL}$ Lonicera japonica extracts for $4 \mathrm{~h}$ and then irradiated with $0.8 \mathrm{~J} / \mathrm{cm}^{2}$ fluence dose. After irradiation, the cells were photographed immediately with an Olympus IX 70 phase-contrast microscopy (300X). A field was chosen in the center of each well at approximately the same location for photography.

2.9. Localization of F-Actin and Tubulin. Qualitative F-actin and tubulin staining was obtained by plating $\mathrm{CH} 27$ cells at $1 \times 10^{5}$ cells per well $48 \mathrm{~h}$. $\mathrm{CH} 27$ cells were incubated with vehicle alone or $100 \mu \mathrm{g} / \mathrm{mL}$ Lonicera japonica extracts for $4 \mathrm{~h}$ and then irradiated with $0.8 \mathrm{~J} / \mathrm{cm}^{2}$ fluence dose. To visualize F-actin, cells were fixed in $3.7 \%$ formaldehyde for $15 \mathrm{~min}$, permeabilized with $1 \%$ Triton X-100 for $10 \mathrm{~min}$, and incubated with $1.9 \times 10^{-7} \mathrm{M}$ TRITC-phalloidin for $40 \mathrm{~min}$. To detect tubulin, cells were incubated for $30 \mathrm{~min}$ with 250 nM Tubulin Tracker Green reagent. After three washings, the cells were observed by Olympus IX 70 fluorescence microscopy (300X).

2.10. Measurement of Mitochondrial Membrane Potential. Mitochondrial membrane potential (MMP) was measured with JC-1 (5,5' ,6,6' ${ }^{\prime}$-tetrachloro-1,1' ${ }^{\prime}, 3,3^{\prime}$-tetraethylbenzimidazolocarbocyanine iodide; Molecular Probe, Eugene, OR). $\mathrm{CH} 27$ cells $\left(1 \times 10^{6}\right)$ were incubated with vehicle alone or $100 \mu \mathrm{g} / \mathrm{mL}$ of Lonicera japonica extracts for $4 \mathrm{~h}$ and then irradiated with $0.8 \mathrm{~J} / \mathrm{cm}^{2}$ light dose. After irradiation, cells were stained with $2 \mu \mathrm{M} \mathrm{JC}-1$ for $30 \mathrm{~min}$, washed with PBS, and analyzed on a flow cytometer (Becton Dickinson, San Joes, CA, USA) using $488 \mathrm{~nm}$ excitation with 530 and $590 \mathrm{~nm}$ bandpass emission filters.

2.11. Measurement of Mitochondrial Permeability Transition (MPT) Pore with Calcein. Cells were seeded at a density of $6 \times 10^{5}$ cells onto $6-\mathrm{cm}$ dish $48 \mathrm{~h}$ before being treated with drugs. $\mathrm{CH} 27$ cells were loaded with $1 \mu \mathrm{M}$ calceinacetomethoxy ester for $30 \mathrm{~min}$ in $1 \mathrm{~mL}$ of DMEM supplemented with $1 \mathrm{mM} \mathrm{CoCl}_{2}$. Cells were washed free of calcein and incubated with vehicle alone or $100 \mu \mathrm{g} / \mathrm{mL}$ Lonicera japonica extracts for $4 \mathrm{~h}$ and then irradiated with $0.8 \mathrm{~J} / \mathrm{cm}^{2}$ fluence dose. After irradiation, the fluorescence intensity of calcein was measured with FACSCanto flow cytometer (excitation, $488 \mathrm{~nm}$; emission, $530 \mathrm{~nm}$; Becton Dickinson) and analyzed using ModFit LT 3.0 Software (Verity Software House, Topsham, ME, USA).

2.12. Statistical Analysis. Standard statistical methods based on Student's $t$-test and regression analysis were used. The results are expressed as percentage \pm S.D. of control.

\section{Results}

3.1. Effects of Photoactivated Lonicera japonica Extracts on the Protein Expression of Anti- and Proapoptotic Members in $\mathrm{CH} 27$ Cells. To investigate the role of anti- or proapoptotic

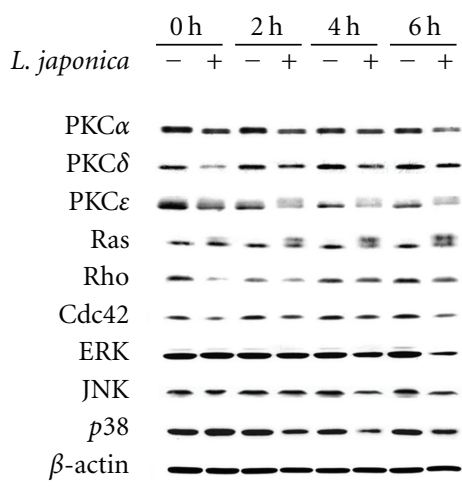

(a)

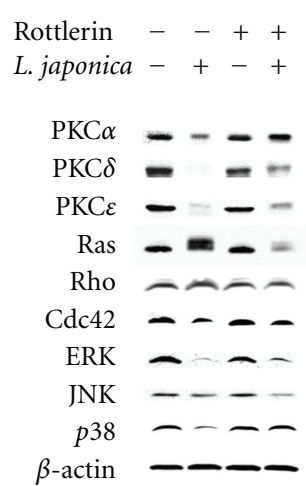

(b)
FIgure 1: (a) The effect of photoactivated Lonicera japonica extracts on the protein expression of PKC, Rho and MAP kinase family members in $\mathrm{CH} 27$ cells. Cells were incubated with $0.1 \%$ ethanol or $100 \mu \mathrm{g} / \mathrm{mL}$ Lonicera japonica extracts for $0,2,4$, and $6 \mathrm{~h}$ and then irradiated with $0.8 \mathrm{~J} / \mathrm{cm}^{2}$ fluence dose. (b) Effects of rottlerin on the photoactivated Lonicera japonica extract-induced changes in the protein expression of PKC, Rho, and MAP kinase family members in $\mathrm{CH} 27$ cells. Cells were pretreated with $10 \mu \mathrm{M}$ rottlerin for $1 \mathrm{~h}$ and then treated with $0.1 \%$ ethanol or Lonicera japonica extracts $(100 \mu \mathrm{g} / \mathrm{mL}, 4 \mathrm{~h})$ and light $\left(0.8 \mathrm{~J} / \mathrm{cm}^{2}\right)$. After irradiation, cell lysates were analyzed by $7 \%(\mathrm{PKC} \alpha, \delta$ and $\varepsilon), 12 \%$ (ERK, JNK and p38) and 14\% (Ras, Rho and Cdc42) SDS-PAGE and then probed with primary antibodies as described in Section 2. -: control cells; + : Lonicera japonica extract- or rottlerin-treated cells. Results are representative of three independent experiments.

members in modulating cell apoptosis induced by photoactivated Lonicera japonica extracts, this study detected the protein expression of $\mathrm{PKC}$, Rho, and MAP kinase family members by Western blot analysis. After treatment of $\mathrm{CH} 27$ cells with $100 \mu \mathrm{g} / \mathrm{mL}$ Lonicera japonica extracts and $0.8 \mathrm{~J} / \mathrm{cm}^{2}$ light dose, the expression of $\mathrm{PKC} \alpha, \mathrm{PKC} \delta, \mathrm{PKC} \varepsilon$, Ras, Rho, Cdc42, ERK, JNK, and p38 proteins significantly decreased in photoactivated Lonicera japonica extract-treated cells within $6 \mathrm{~h}$ (Figure 1(a)). As shown in Figure 1(a), treatment of cells with $0.1 \%$ ethanol and light did not affect the protein expression. It is noteworthy that the protein expression of Ras exhibits two bands ( 21 and $22 \mathrm{kDa}$ ). The amount of the band of $22 \mathrm{kDa}$ significantly increased after treatment with Lonicera japonica extracts and light (Figure 1(a)).

\subsection{Effects of Rottlerin on the Photoactivated Lonicera japonica} Extract-Induced CH27 Cell Death. These above data indicated that the protein expression of $\mathrm{PKC} \delta$ was involved in photoactivated Lonicera japonica extract-induced cell death. However, PKC $\delta$ cleavage and activation has been reported as a proapoptotic response to various apoptotic stimuli. To further investigate whether $\mathrm{CH} 27$ cell death induced by treatment with Lonicera japonica extracts and light could be linked to the activation of PKC $\delta$ expression, we determined the effect of PKC $\delta$-selective inhibitor rottlerin on the photoactivated Lonicera japonica extract-induced $\mathrm{CH} 27$ cell death. As shown in Figure 2(a), the photoactivated Lonicera japonica extract-induced $\mathrm{CH} 27$ cell death was blocked by 
pretreatment with $10 \mu \mathrm{M}$ rottlerin for $1 \mathrm{~h}$. Furthermore, pretreatment of $\mathrm{CH} 27$ cells with $10 \mu \mathrm{M}$ rottlerin could inhibit the photoactivated Lonicera japonica extract-induced changes in cell morphology (Figure 2(b)). In light-shield condition, Lonicera japonica extracts $(100 \mu \mathrm{g} / \mathrm{mL}, 4 \mathrm{~h})$ did not exhibit significant cell toxicity following MTT assay (data not shown). Light alone did not affect cell survival in this study (Figure 2(b)). We also demonstrated that rottlerin significantly reversed the photoactivated Lonicera japonica extract-mediated decrease in protein expression of $\mathrm{PKC} \alpha$, $\mathrm{PKC} \delta, \mathrm{PKC} \varepsilon, \mathrm{ERK}$, and p38 (Figure 1(b)).

\subsection{Effects of Rottlerin on the Photoactivated Lonicera japonica} Extract-Induced Changes in the Localization of Cytoskeleton in CH27 Cells. In this study, the effect of rottlerin on the photoactivated Lonicera japonica extract-induced changes in $\mathrm{CH} 27$ cell actin microfilaments was examined. As shown in Figure 3, the photoactivated Lonicera japonica extractinduced disruption of actin microfilaments was prevented by pretreatment of $\mathrm{CH} 27$ cells with $10 \mu \mathrm{M}$ rottlerin. In the control, actin microfilaments were diffusely present as short microfilaments throughout the $\mathrm{CH} 27$ cells (Figure 3 ). Rottlerin-treated cells had a similar appearance to those in the control (Figure 3 ). In addition to actin microfilaments, microtubules are widely recognized as key components of the cytoskeleton. To further examine whether the microtubules were injured by photoactivated Lonicera japonica extracts in CH27 cells, TubulinTracker Green reagent, which is highly selective for polymerized tubulin, was used. In this study, tubulin organized into discrete aggregates dispersed randomly throughout the cytoplasm and concentrated prominently on the nucleus margins after treatment with Lonicera japonica extracts and light (Figure 3 ). The effect of rottlerin on the photoactivated Lonicera japonica extract-induced changes in $\mathrm{CH} 27$ cell tubulin was also examined. As shown in Figure 3, rottlerin $(10 \mu \mathrm{M})$ significantly inhibited the photoactivated Lonicera japonica extract-induced changes in the organization and distribution of tubulin (Figure 3 ).

3.4. Effects of Rottlerin on the Photoactivated Lonicera japonica Extract-Induced Changes in Protein Expression of Cytoskeleton-Related Proteins in CH27 Cells. Results described above suggested that the photoactivated Lonicera japonica extract-induced apoptosis is mediated by change in distribution of cytoskeleton. Therefore, we focused the attention on the expression of cytoskeleton-related proteins, such as tubulin, focal adhesion kinase (FAK), paxillin, and heat shock protein (HSP27). As shown in Figure 4(a), the expression of tubulin, FAK, paxillin, and HSP27 was significantly decreased after treatment with $100 \mu \mathrm{g} / \mathrm{mL}$ Lonicera japonica and irradiation with $0.8 \mathrm{~J} / \mathrm{cm}^{2}$ light dose. The photoactivated Lonicera japonica-induced decrease in tubulin, FAK, paxillin, and HSP27 protein levels was partly reversed by pretreatment with $10 \mu \mathrm{M}$ rottlerin (Figure $4(\mathrm{~b})$ ).

\subsection{Effects of Rottlerin on the Photoactivated Lonicera japonica} Extract-Induced Changes in Mitochondrial Function in CH27 Cells. In the experiments following, the effect of photoactivated Lonicera japonica extracts on mitochondrial membrane

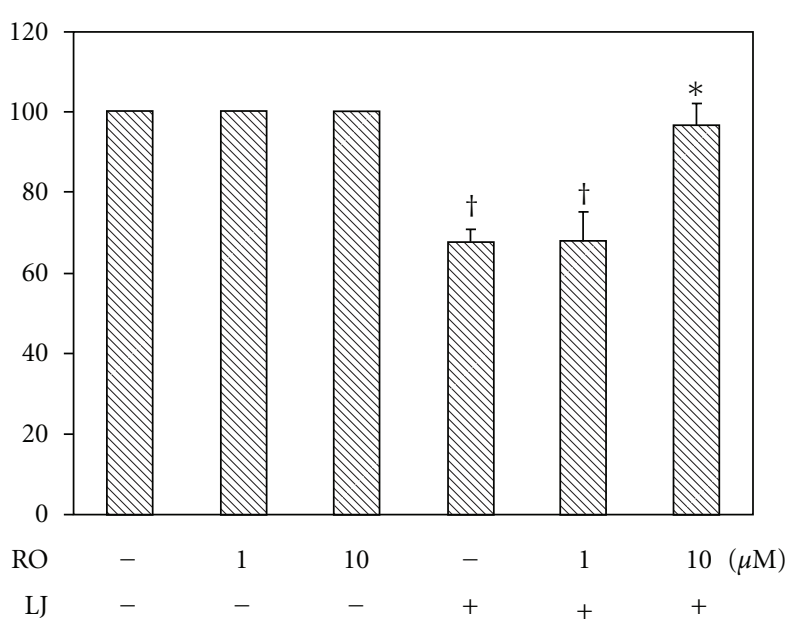

(a)

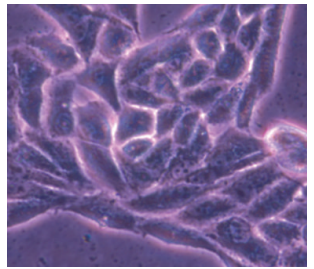

(i)

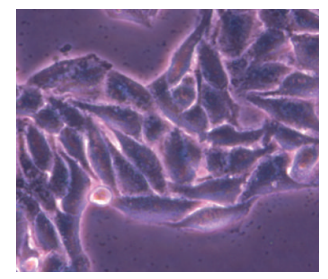

(iii)

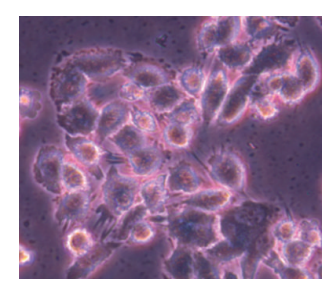

(ii)

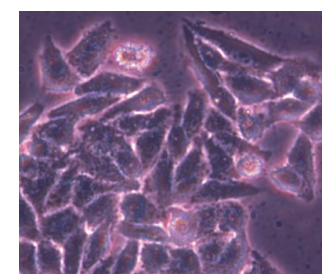

(iv) (b)

FIGURE 2: Effects of rottlerin on the photoactivated Lonicera japonica extract-induced cell death and changes in cell morphology. Cells were pretreated with $10 \mu \mathrm{M}$ rottlerin (RO) for $1 \mathrm{~h}$ and then treated with $0.1 \%$ ethanol or $100 \mu \mathrm{g} / \mathrm{mL}$ Lonicera japonica extracts (LJ) for $4 \mathrm{~h}$ and $0.8 \mathrm{~J} / \mathrm{cm}^{2}$ light dose. (a) After irradiation, the viable cells were measured by MTT assay. Results are expressed as the mean percentage of control \pm S.D. ${ }^{\dagger} P<.01$ compared to the control values. ${ }^{*} P<.01$ compared to the photoactivated Lonicera japonica extract-treated cells. (b) Morphological analysis by phase-contrast microscopy of $\mathrm{CH} 27$ cells. After irradiation, the cells were immediately photographed. (i) control cells; (ii) Lonicera japonica-treated cells; (iii) rottlerin-treated cells; (iv) cells were pretreated with rottlerin and then Lonicera japonica. All results are representative of three independent experiments.

potential of $\mathrm{CH} 27$ cells was examined. The mitochondrial membrane potential was investigated with the fluorescent probe JC-1. After cells were treated with $100 \mu \mathrm{g} / \mathrm{mL}$ Lonicera japonica extracts for $4 \mathrm{~h}$ and then irradiated with $0.8 \mathrm{~J} / \mathrm{cm}^{2}$ fluence dose, a remarkable attenuation of mitochondrial membrane potential occurred compared to the control cells (Figure 5(a)). As shown in Figure 5(a), photoactivated Lonicera japonica extracts induced a marked decrease in red 

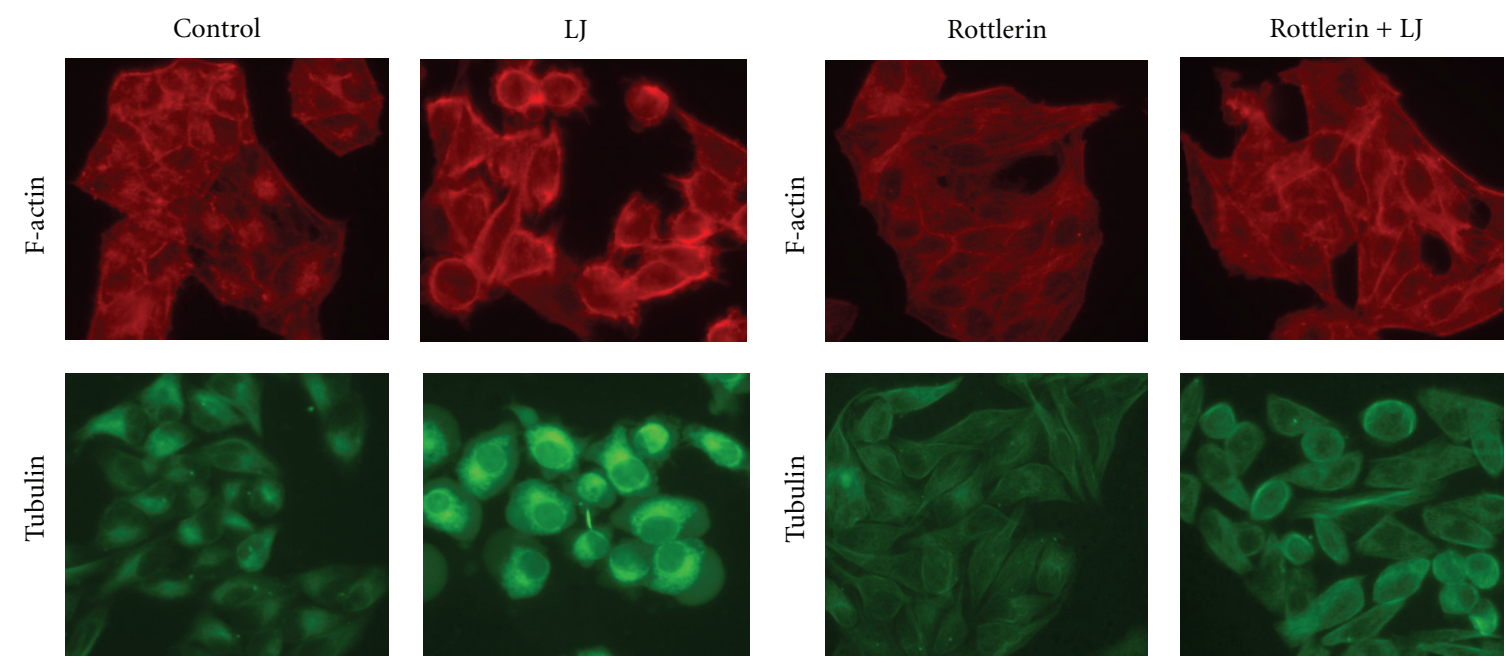

FIGURE 3: Effects of rottlerin on the photoactivated Lonicera japonica extract-induced changes in cytoskeleton in CH27 cells. Cells were incubated with $0.1 \%$ ethanol or $100 \mu \mathrm{g} / \mathrm{mL}$ Lonicera japonica extracts (LJ) for $4 \mathrm{~h}$ and then irradiated with $0.8 \mathrm{~J} / \mathrm{cm}^{2} \mathrm{fluence}$ dose. In rottlerin treatment, cells were pretreated with a final concentration of $10 \mu \mathrm{M}$ rottlerin for $1 \mathrm{~h}$. F-actin microfilaments in CH27 cells was visualized by TRITC-labeled phalloidin binding. To detect tubulin distribution, cells were incubated for 30 min with $250 \mathrm{nM}$ Tubulin Tracker Green reagent. The specimens were observed by fluorescence microscopy (300X). Results are representative of three independent experiments.

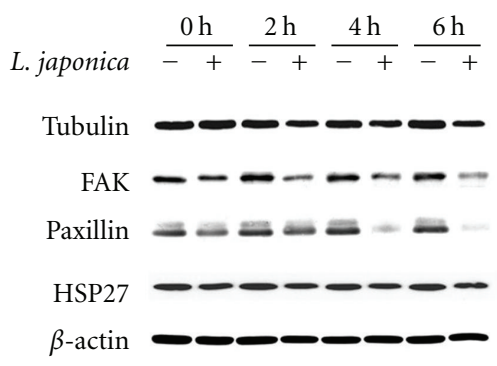

(a)

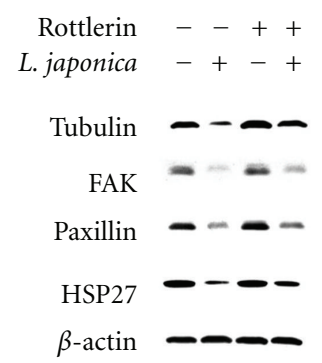

(b)
FIGURE 4: (a) Effects of photoactivated Lonicera japonica extracts on the expression of cytoskeleton-related proteins in $\mathrm{CH} 27$ cells. Cells were incubated with $0.1 \%$ ethanol or $100 \mu \mathrm{g} / \mathrm{mL}$ Lonicera japonica extracts for $0,2,4$, and $6 \mathrm{~h}$ and then irradiated with $0.8 \mathrm{~J} / \mathrm{cm}^{2}$ fluence dose. (b) The effect of rottlerin on the photoactivated Lonicera japonica extract-induced changes in cytoskeleton-related proteins expression of $\mathrm{CH} 27$ cells. Cells were pretreated with $10 \mu \mathrm{M}$ rottlerin for $1 \mathrm{~h}$ and then treated with $0.1 \%$ ethanol or $100 \mu \mathrm{g} / \mathrm{mL}$ Lonicera japonica extracts for $4 \mathrm{~h}$ and $0.8 \mathrm{~J} / \mathrm{cm}^{2}$ fluence dose. After irradiation, cell lysates were analyzed by $5 \%$ (FAK), 9\% (paxillin), $10 \%$ (tubulin), and 13\% (HSP27) SDS-PAGE and then probed with primary antibodies as described in Section 2. -: control cells; +: Lonicera japonica extract- or rottlerin-treated cells. Results are representative of three independent experiments.

fluorescence intensity compared to those in control cells. The photoactivated Lonicera japonica-induced disruption of mitochondrial membrane potential was partly blocked by pretreatment with $10 \mu \mathrm{M}$ rottlerin (Figure 5(a)). To further confirm the possible involvement of mitochondrial permeability transition (MPT) pores in the process of the photoactivated Lonicera japonica extract-induced apoptosis, we measured the opening of MPT pore in intact cells by flow cytometry. As shown in Figure 5(b), treatment with $100 \mu \mathrm{g} / \mathrm{mL}$ Lonicera japonica extracts for $4 \mathrm{~h}$ and irradiation with $0.8 \mathrm{~J} / \mathrm{cm}^{2}$ light dose resulted in the formation of a group of cells with lower calcein fluorescence intensity due to the opening of MPT pores. Rottlerin alone also showed the same phenomenon as the Lonicera japonica extract-sensitized/irradiated CH27 cells (Figure 5(b)). The photoactivated Lonicera japonica extract-induced the opening of MPT pore was not enhanced by pretreatment with $10 \mu \mathrm{M}$ rottlerin (Figure 5(b)). Based on the above data, mitochondrial function was involved in the photoactivated Lonicera japonica extract-induced $\mathrm{CH} 27$ cell death.

\section{Discussion}

Many factors such as cytoskeleton-related proteins, protein kinase C (PKC) family, Rho family, and mitogen-activated protein kinase (MAP kinase) family have been demonstrated to be involved in apoptosis. PKC family, which functions through serine/threonine kinase activity, is involved in signal transduction pathways necessary for cell proliferation, differentiation, and apoptosis $[12,13]$. PKC $\delta$ has been reported as a proapoptotic response to various apoptotic stimuli, such as radiation and chemotherapeutic agents [14, 15], whereas $\mathrm{PKC} \alpha$ and $\mathrm{PKC} \varepsilon$ have been mainly associated with antiapoptotic effects $[16,17]$. A familiar signaling pathway is the MAP kinase cascades which play a central role in the cellular response to various extracellular stimuli $[18,19]$. Three subgroups of MAPKs are known: extracellular signalregulated kinases (ERK1/2), jun N-terminal kinase/stressactivated protein kinase (JNK/SAPK), and p38. Activation of MAP kinase members has been implicated in the regulation of apoptotic cell death $[18,20]$. Furthermore, PKC is known to activate ERK1/2 pathway by stimulating the Ras-RafMAP kinase/ERK kinase-ERK pathway [21, 22]. Mhaidat 


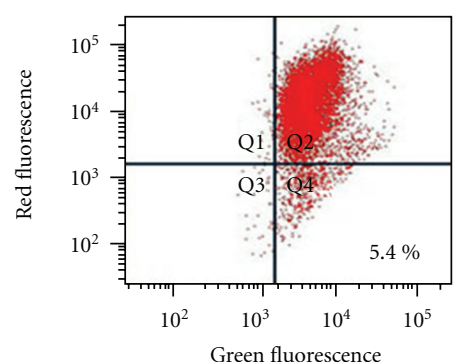

(i)

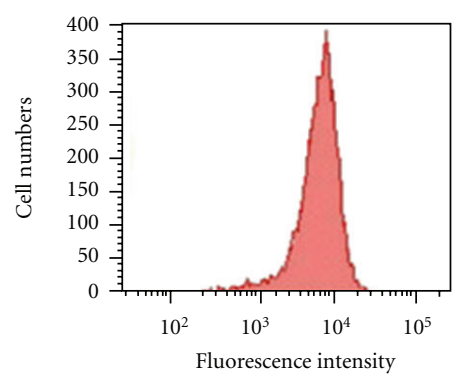

(i)

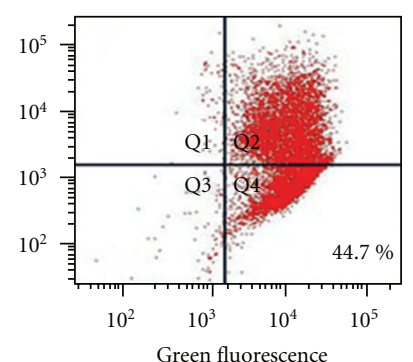

(ii)

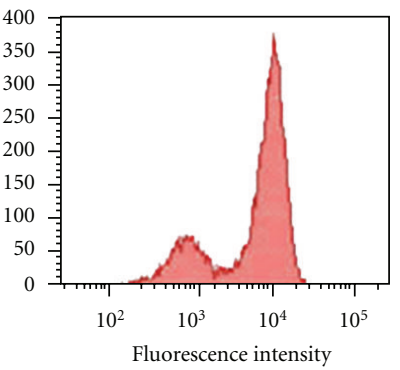

(ii)

(a)

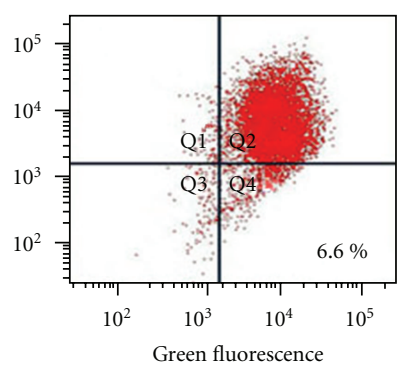

(iii)

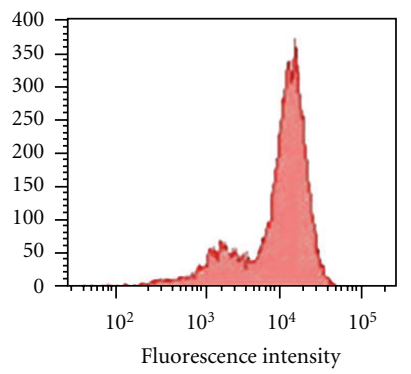

(iii)

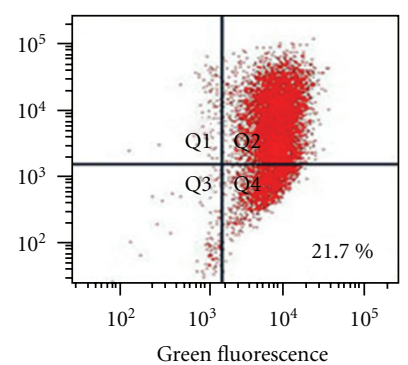

(iv)

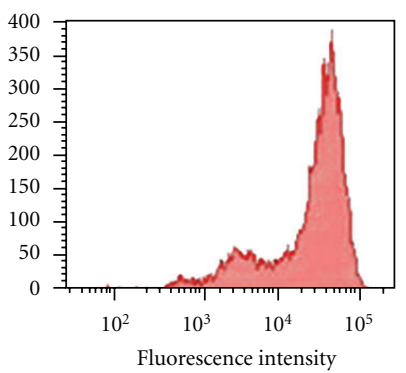

(iv)

(b)

FIGURE 5: Effects of rottlerin on the photoactivated Lonicera japonica extract-induced disruption of mitochondrial function in CH27 cells. Cells were incubated with vehicle alone or $100 \mu \mathrm{g} / \mathrm{mL}$ Lonicera japonica extracts for $4 \mathrm{~h}$ and then irradiated with $0.8 \mathrm{~J} / \mathrm{cm}^{2}$ fluence dose. In rottlerin treatment, cells were pretreated with a final concentration of $10 \mu \mathrm{M}$ rottlerin for $1 \mathrm{~h}$. (a) The fluorescent cation dye JC- 1 was used to determine the mitochondrial membrane potential. After irradiation, the cells were harvested and stained with $2 \mu \mathrm{M} \mathrm{JC}-1$ for $15 \mathrm{~min}$. The mitochondrial depolarization patterns of the CH27 cells were measured by flow cytometry. The sum of the percentage of Q1, Q2, Q3, and Q4 is $100 \%$. (b) The effect of rottlerin on the photoactivated Lonicera japonica extract-induced opening of mitochondrial permeability transition (MPT) pore in $\mathrm{CH} 27$ cells. Before treatment with Lonicera japonica extracts and light, cells were loaded with $1 \mu \mathrm{M}$ calcein AM for $30 \mathrm{~min}$ in DMEM medium containing $1 \mathrm{mM} \mathrm{CoCl}_{2}$. After irradiation, the cells were harvested and then analyzed by flow cytometry for loss of fluorescence intensity due to efflux of the dye. (i) control cells; (ii) Lonicera japonica extract-treated cells; (iii) rottlerin-treated cells; (iv) cells were pretreated with rottlerin and then Lonicera japonica extracts. Results are representative of three independent experiments.

et al. (2007) have suggested that PKC $\varepsilon$ is acting upstream of docetaxel-induced ERK1/2 activation [23]. Ras, a small GTPase protein, is an important regulator of cell growth in all eukaryotic cells. Ras mediates its effects on cell proliferation and apoptosis in part by activation of the Raf/MEK/ERK cascade of protein kinases [24, 25]. The Rho family members are small GTPases and key regulators of actin dynamics, together with the related proteins Rho and Cdc42, coordinating formation of stress fibers, focal adhesions, lamelipodia, and filopodia and thus regulating overall cellular movement and cell morphology [26, 27]. To identify the overall signaling pathways involved in photoactivated Lonicera japonica-induced $\mathrm{CH} 27$ cell apoptosis, we examined most proteins expression of apoptotic signaling pathways such as PKC, Rho, and MAP kinase family members in this study.

In this study, there was a significant decrease in protein expression of PKC, Rho, and MAP kinase family members after treatment with Lonicera japonica extracts and light. The results of PKC protein expression are consistent with those of other studies reporting that the overexpression and activation of $\mathrm{PKC} \alpha$ and $\mathrm{PKC} \varepsilon$ have been mainly associated with inhibition of apoptosis $[16,17]$. Proteolytic cleavage of PKC $\delta$ by caspase- 3 at the V3 (hinge) domain of the enzyme releases a catalytically active fragment of approximately $40 \mathrm{kDa}$. It is generally believed that proteolytic activation of PKC $\delta$ is responsible for apoptotic execution [14, 15]. However, this study could not detect the presence of PKC $\delta$ catalytic fragment after Lonicera japonica extracts with irradiation. In this study, $\mathrm{PKC} \varepsilon$ is clearly identified as a doublet with molecular masses about $90 \mathrm{kDa}$. PKCe has often been detected as a doublet, but this has been rarely commented on $[28,29]$. It has also been demonstrated that $\mathrm{PKC} \varepsilon$ purified from rat brain migrates as two distinct bands with molecular masses of $93 \mathrm{kDa}$ and $96 \mathrm{kDa}$; on phosphatase treatment, these are reduced to a single $90 \mathrm{kDa}$ species [30]. Rottlerin reversed the photoactivated Lonicera japonica extract-induced change in PKC protein expression. Based on the above data, it seemed reasonable to surmise that prevention of $\mathrm{CH} 27$ cells from the photoactivated Lonicera japonica extract-induced cell death of rottlerin is associated with the activity of PKC family. 
In this study, it was also found that rottlerin reversed the protein expression of many kinases of prosurvival signaling pathway, such as Ras, ERK, and p38, during the photoactivated Lonicera japonica extract-induced cell death. It is noteworthy that Western blot analysis of the protein expression of Ras exhibits two bands ( 21 and $22 \mathrm{kDa}$ ) in this study. The amount of $21 \mathrm{kDa}$ of Ras significantly decreased after treatment of $\mathrm{CH} 27$ cells with Lonicera japonica extracts and light, whereas the protein expression of $22 \mathrm{kDa}$ of Ras was increased. It is wellknown that Ras prenylation in which a lipid anchor is added to the C-terminus of proteins to allow membrane association plays a central role in the development of cancer. When the prenylation of Ras was blocked, a shift to a higher mobility band was seen on SDSPAGE $[31,32]$. The protein bands of 21 and $22 \mathrm{kDa}$ of Ras may be its prenylated and unprenylated status, respectively. Therefore, we guess that photoactivated Lonicera japonica extracts induced $\mathrm{CH} 27$ cell death through blocking the prenylation of Ras.

Several reports have indicated that cytoskeleton may play a primary role in the initiation phase of apoptosis in certain circumstances $[4,5]$. Microtubules and actin microfilaments are the major proteins of cytoskeleton and both regulate cell shape. The involvement of cytoskeletal actin in the photoactivated Lonicera japonica extractinduced apoptosis has been suggested by our previous study [3]. In this study, the photoactivated Lonicera japonica extract-induced disruption of actin microfilaments was prevented by pretreatment of $\mathrm{CH} 27$ cells with rottlerin. In addition to actin microfilaments, the microtubule also serves as key components of the cytoskeleton. This study demonstrated that rottlerin prevented the photoactivated Lonicera japonica extract-induced changes in the protein amount and distribution of tubulin. These data suggest that rottlerin can prevent the photoactivated Lonicera japonicainduced rearrangements of the actin microfilaments or microtubules and support the possibility that rottlerin, directly or indirectly, prevents the aggregation of cytoskeleton and stabilizes the CH27 cell cytoskeleton. HSP27 is a component of the large and heterogeneous group of chaperone proteins, and its main functions are prevention of aggregation of actin filament and inhibition of apoptosis [33]. It has been suggested that p38-mediated Factin reorganization was associated with translocation of HSP27 from cytosolic to cytoskeletal fraction [34]. The photoactivated Lonicera japonica-induced decrease in p38 and HSP27 protein expression was significantly reversed by rottlerin in this study. This result suggested that the protein expression of p38 and HSP27, which may stabilize the actin cytoskeleton, may be one of the mechanisms for the protective effects of rottlerin against the photoactivated Lonicera japonica-induced $\mathrm{CH} 27$ cell death. In this study, the change in the protein expression of cytoskeleton-related proteins, such as tubulin, FAK, paxillin, and HSP27 was significantly observed in photosensitized Lonicera japonica extract-induced rapid cell death. Many intracellular events, including the assembly of focal adhesion, actin microfilament reorganization, and recruitment of many signaling molecules to the focal adhesions were involved in the change in cell shape [3-5]. This study also demonstrated that photoactivated Lonicera japonica extracts induced a marked morphological change, where normally flat cells became round in shape and detached from the extracellular matrix. This finding suggested that the photoactivated Lonicera japonica extract-induced cell death and changes in cell morphology are mediated in part through its effect on cytoskeleton in $\mathrm{CH} 27$ cells. The present study also demonstrated that the photoactivated Lonicera japonica extract-induced $\mathrm{CH} 27$ cell death and changes in cell morphology were blocked by pretreatment with $10 \mu \mathrm{M}$ rottlerin.

Many evidences indicated the potential role of actin cytoskeleton in facilitating the mitochondrial recruitment of various proapoptotic proteins, such as cytochrome $c$ or apoptosis-inducing factor, to the cytosol to initiate apoptosis [5-7]. The mitochondrial permeability transition (MPT) pore is characterized by opening of the permeability transition pore in the inner mitochondrial membrane, which results in an increase in permeability of this membrane to protons, ions, and small molecular weight solutes [35]. Therefore, the opening of MPT pore is a critical step in the process that allows mitochondria to release cytochrome $c$ or apoptosis-inducing factor into the cytoplasm $[36,37]$. This increased permeability is also considered to lead to a collapse of the mitochondrial membrane potential. We demonstrated that exposing the $\mathrm{CH} 27$ cells to Lonicera japonica extracts and light resulted in a significant induce of the opening of MPT pores accompanied by a disruption of mitochondrial membrane potential in $\mathrm{CH} 27$ cells. Therefore, we hypothesize that the photoactivated Lonicera japonica extract-mediated apoptosis occurs through the disruption of mitochondrial function. We also demonstrated that the photoactivated Lonicera japonica extract-induced disruption of mitochondrial membrane potential was significantly blocked by pretreatment with rottlerin. Rottlerin had a slight effect on the photoactivated Lonicera japonica extractinduced opening of MPT pores. Based on the above data, the opening of MPT pore may be involved in photoactivated Lonicera japonica extract-induced $\mathrm{CH} 27$ cell apoptosis, but not a major factor. However, pretreatment of $\mathrm{CH} 27$ cells with rottlerin could prevent the photoactivated Lonicera japonica extract-induced disruption of mitochondrial membrane potential, providing further support for the role of PKC $\delta$ as a mediating factor of mitochondria during the photoactivated Lonicera japonica extract-induced cell apoptosis.

This study indicated that many apoptotic signaling pathways, such as Rho family, PKC family, MAP kinase family, and mitochondria-mediated apoptotic pathway, were triggered by Lonicera japonica extracts and irradiation in $\mathrm{CH} 27$ cells. Our findings suggested that promotion of the cytoskeleton-related signaling cascade following rottlerin by upregulation of cytoskeleton-related mediators (p38, HSP27, FAK, paxillin and tubulin) and molecules of downstream of F-actin (mitochondria-mediated apoptosis pathway) reduce $\mathrm{CH} 27$ cell death, indicating that cytoskeleton is the potential target in the photoactivated Lonicera japonica extractinduced $\mathrm{CH} 27$ cell apoptosis. 


\section{Acknowledgments}

This work was supported by National Science Council [NSC 97-2320-B-039-005-MY3] and China Medical University [CMU97-128].

\section{References}

[1] B. U. Jones, M. Helmy, M. Brenner et al., "Photodynamic therapy for patients with advanced non-small-cell carcinoma of the lung," Clinical Lung Cancer, vol. 3, no. 1, pp. 37-41, 2001.

[2] J. S. McCaughan Jr., "Survival after photodynamic therapy to non-pulmonary metastatic endobronchial tumors," Lasers in Surgery and Medicine, vol. 24, no. 3, pp. 194-201, 1999.

[3] H. W. C. Leung, M. J. Hour, W. T. Chang et al., "P38-associated pathway involvement in apoptosis induced by photodynamic therapy with Lonicera japonica in human lung squamous carcinoma CH27 cells," Food and Chemical Toxicology, vol. 46, no. 11, pp. 3389-3400, 2008.

[4] G. Godman, B. Woda, R. Kolberg, and S. Berl, "Redistribution of contractile and cytoskeletal components induced by cytochalasin. II. In HeLa and HEp2 cells," European Journal of Cell Biology, vol. 22, no. 2, pp. 745-754, 1980.

[5] H.-Z. Lee, W.-H. Yang, M.-J. Hour et al., "Photodynamic activity of aloe-emodin induces resensitization of lung cancer cells to anoikis," European Journal of Pharmacology, vol. 648, no. $1-3$, pp. 50-58, 2010.

[6] B. W. Bernstein and J. R. Bamburg, "Actin-ATP hydrolysis is a major energy drain for neurons," Journal of Neuroscience, vol. 23, no. 1, pp. 1-6, 2003.

[7] B. W. Bernstein, H. Chen, J. A. Boyle, and J. R. Bamburg, "Formation of actin-ADF/cofilin rods transiently retards decline of mitochondrial potential and ATP in stressed neurons," American Journal of Physiology —Cell Physiology, vol. 291, no. 5, pp. C828-C839, 2006.

[8] M. Gschwendt, H. J. Muller, K. Kielbassa et al., "Rottlerin, a novel protein kinase inhibitor," Biochemical and Biophysical Research Communications, vol. 199, no. 1, pp. 93-98, 1994.

[9] S. P. Soltoff, "Rottlerin: an inappropriate and ineffective inhibitor of PKC8," Trends in Pharmacological Sciences, vol. 28, no. 9, pp. 453-458, 2007.

[10] S. P. Soltoff, "Rottlerin is a mitochondrial uncoupler that decreases cellular ATP levels and indirectly blocks protein kinase C $\delta$ tyrosine phosphorylation," Journal of Biological Chemistry, vol. 276, no. 41, pp. 37986-37992, 2001.

[11] M.-J. Xie, H. Chang, Y.-Y. Wang et al., "Evidence that apoptotic signalling in hypertrophic cardiomyocytes is determined by mitochondrial pathways involving protein kinase $\mathrm{C} \delta$," Clinical and Experimental Pharmacology and Physiology, vol. 37, no. 12, pp. 1120-1128, 2010.

[12] P. Acs, K. Bögi, P. S. Lorenzo et al., "The Catalytic domain of protein kinase $\mathrm{C}$ chimers modulates the aAffinity and targeting of phorbol ester-induced translocation," Journal of Biological Chemistry, vol. 72, pp. 22148-22153, 1993.

[13] L. E. Kilpatrick, S. Sun, D. Mackie, F. Baik, H. Li, and H. M. Korchak, "Regulation of TNF mediated antiapoptotic signaling in human neutrophils: role of $\delta$-PKC and ERK1/2," Journal of Leukocyte Biology, vol. 80, no. 6, pp. 1512-1521, 2006.

[14] N. Mitsutake, H. Namba, S. S. Shklyaev et al., "PKC $\delta$ mediates ionizing radiation-induced activation of c-Jun NH2-terminal kinase through MKK7 in human thyroid cells," Oncogene, vol. 20, no. 8, pp. 989-996, 2001.

[15] M. E. Reyland, S. M. Anderson, A. A. Matassa, K. A. Barzen, and D. O. Quissell, "Protein kinase C $\delta$ is essential for etoposide-induced apoptosis in salivary gland acinar cells," Journal of Biological Chemistry, vol. 274, no. 27, pp. 1911519123, 1999.

[16] D. Lu, U. Sivaprasad, J. Huang, E. Shankar, S. Morrow, and A. Basu, "Protein kinase C- $\varepsilon$ protects MCF-7 cells from TNF-mediated cell death by inhibiting Bax translocation," Apoptosis, vol. 12, no. 10, pp. 1893-1900, 2007.

[17] P. P. Ruvolo, X. Deng, B. K. Carr, and W. S. May, "A functional role for mitochondrial protein kinase $\mathrm{C} \alpha$ in $\mathrm{Bcl} 2$ phosphorylation and suppression of apoptosis," Journal of Biological Chemistry, vol. 273, no. 39, pp. 25436-25442, 1998.

[18] Y. Liu, K. Z. Guyton, M. Gorospe, Q. Xu, J. C. Lee, and N. J. Holbrook, "Differential activation of ERK, JNK/SAPK and P38/CSBP/RK map kinase family members during the cellular response to arsenite," Free Radical Biology and Medicine, vol. 21, no. 6, pp. 771-781, 1996.

[19] J. Raingeaud, S. Gupta, J. S. Rogers et al., "Pro-inflammatory cytokines and environmental stress cause p38 mitogenactivated protein kinase activation by dual phosphorylation on tyrosine and threonine," Journal of Biological Chemistry, vol. 270, no. 13, pp. 7420-7426, 1995.

[20] F. T. Yeh, C. H. Wu, and H. Z. Lee, "Signaling pathway for aloeemodin-induced apoptosis in human H460 lung nonsmall carcinoma cell," International Journal of Cancer, vol. 106, no. 1, pp. 26-33, 2003.

[21] A. Goerke, N. Sakai, E. Gutjahr et al., "Induction of apoptosis by protein kinase $\mathrm{C} \delta$ is independent of its kinase activity," Journal of Biological Chemistry, vol. 277, no. 35, pp. 3205432062, 2002.

[22] M. Tafani, J. A. Cohn, N. O. Karpinich, R. J. Rothman, M. A. Russo, and J. L. Farber, "Regulation of intracellular $\mathrm{pH}$ mediates Bax activation in HeLa cells treated with staurosporine or tumor necrosis factor- $\alpha$," Journal of Biological Chemistry, vol. 277, no. 51, pp. 49569-49576, 2002.

[23] N. M. Mhaidat, R. F. Thorne, D. Z. Xu, and P. Hersey, "Regulation of docetaxel-induced apoptosis of human melanoma cells by different isoforms of protein kinase C," Molecular Cancer Research, vol. 5, no. 10, pp. 1073-1081, 2007.

[24] F. Chang, L. S. Steelman, and J. A. McCubrey, "Raf-induced cell cycle progression in human TF-1 hematopoietic cells," Cell Cycle, vol. 1, no. 3, pp. 220-226, 2002.

[25] K. Korotayev, M. Chaussepied, and D. Ginsberg, "ERK activation is regulated by E2F1 and is essential for E2F1induced S phase entry," Cellular Signalling, vol. 20, no. 6, pp. 1221-1226, 2008.

[26] A. Hall, "Rho GTPases and the control of cell behaviour," Biochemical Society Transactions, vol. 33, no. 5, pp. 891-895, 2005.

[27] C. D. Nobes and A. Hall, "Rho, Rac, and Cdc42 GTPases regulate the assembly of multimolecular focal complexes associated with actin stress fibers, lamellipodia, and filopodia," Cell, vol. 81, no. 1, pp. 53-62, 1995.

[28] A. M. Cacace, S. Nichols Guadagno, R. S. Krauss, D. Fabbro, and I. B. Weinstein, "The epsilon isoform of protein kinase C is an oncogene when overexpressed in rat fibroblasts," Oncogene, vol. 8, no. 8, pp. 2095-2104, 1993.

[29] M. Ueffing, J. Lovrić, A. Philipp, H. Mischak, and W. Kolch, "Protein kinase C- $\varepsilon$ associates with the Raf-1 kinase and induces the production of growth factors that stimulate Raf1 activity," Oncogene, vol. 15, no. 24, pp. 2921-2927, 1997. 
[30] H. Koide, K. Ogita, U. Kikkawa, and Y. Nishizuka, "Isolation and characterization of the $\varepsilon$ subspecies of protein kinase $C$ from rat brain," Proceedings of the National Academy of Sciences of the United States of America, vol. 89, no. 4, pp. 1149-1153, 1992.

[31] M. Geryk-Hall, Y. Yang, and D. P. M. Hughes, "Driven to death: inhibition of farnesylation increases Ras activity in osteosarcoma and promotes growth arrest and cell death," Molecular Cancer Therapeutics, vol. 9, no. 5, pp. 1111-1119, 2010.

[32] K. A. Cengel, K. R. Voong, S. Chandrasekaran et al., "Oncogenic K-Ras signals through epidermal growth factor receptor and wild-type $\mathrm{H}$-Ras to promote radiation survival in pancreatic and colorectal carcinoma cells," Neoplasia, vol. 9, no. 4, pp. 341-348, 2007.

[33] C. Sarto, C. Valsecchi, F. Magni et al., "Expression of heat shock protein 27 in human renal cell carcinoma," Proteomics, vol. 4, no. 8, pp. 2252-2260, 2004.

[34] T. Okada, H. Otani, Y. Wu et al., "Role of F-actin organization in p38 MAP kinase-mediated apoptosis and necrosis in neonatal rat cardiomyocytes subjected to simulated ischemia and reoxygenation," American Journal of Physiology-Heart and Circulatory Physiology, vol. 289, no. 6, pp. H2310-H2318, 2005.

[35] M. Zoratti and I. Szabo, "The mitochondrial permeability transition," Biochimica et Biophysica Acta, vol. 1241, no. 2, pp. 139-176, 1995.

[36] J. J. Lemasters, "Dying a thousand deaths: redundant pathways from different organelles to apoptosis and necrosis," Gastroenterology, vol. 129, no. 1, pp. 351-360, 2005.

[37] N. Zamzami, S. A. Susin, P. Marchetti et al., "Mitochondrial control of nuclear apoptosis," Journal of Experimental Medicine, vol. 183, no. 4, pp. 1533-1544, 1996. 


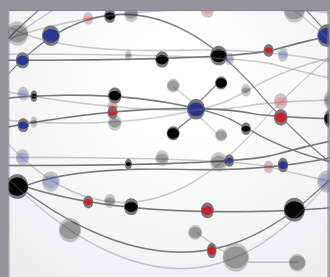

The Scientific World Journal
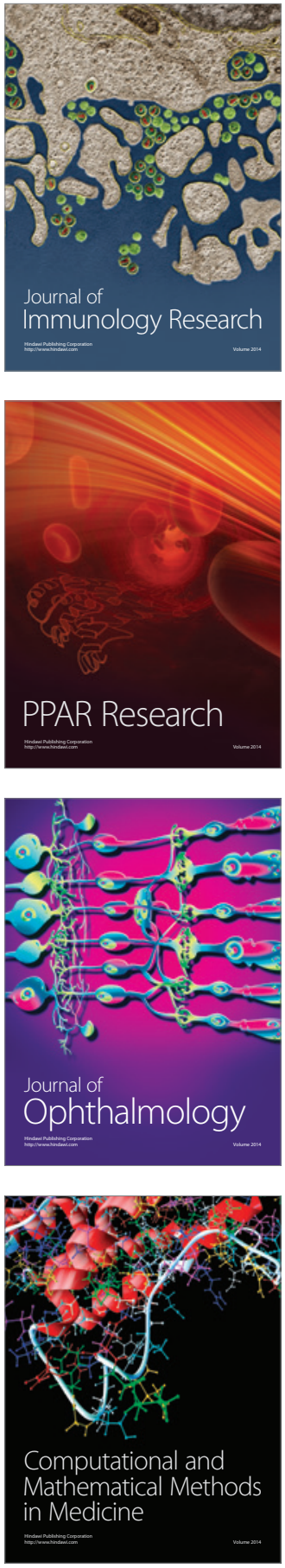

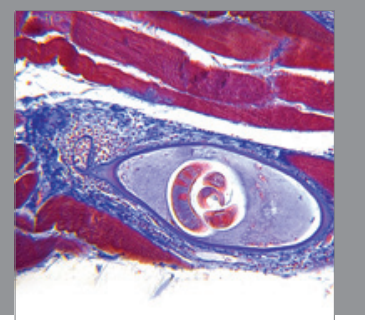

Gastroenterology

Research and Practice
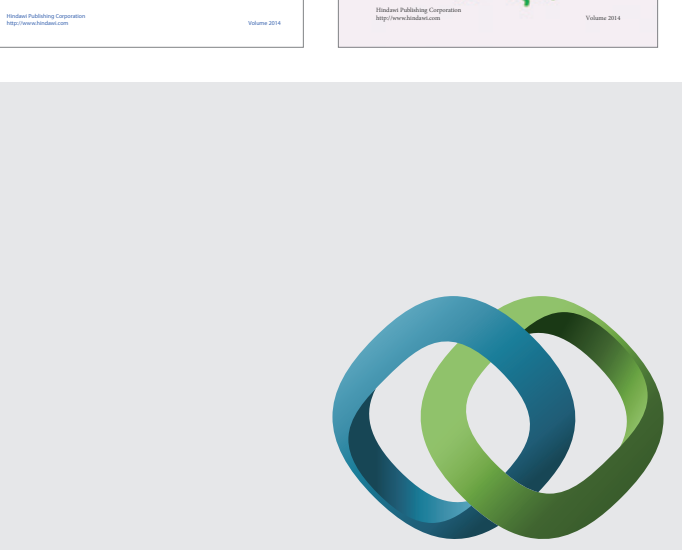

\section{Hindawi}

Submit your manuscripts at

http://www.hindawi.com
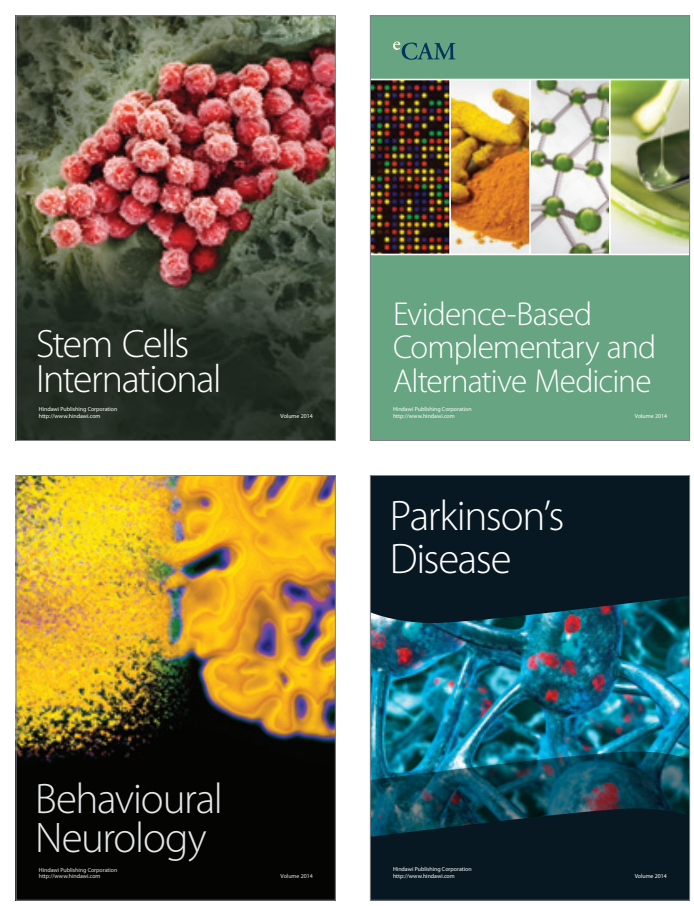

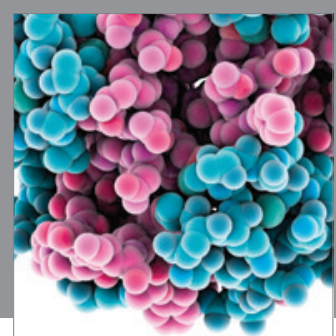

Journal of
Diabetes Research

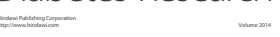

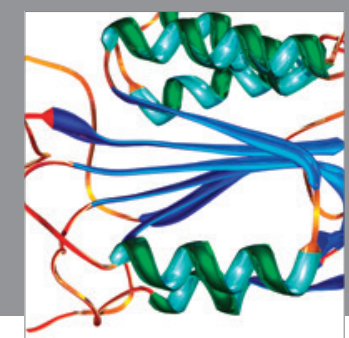

Disease Markers
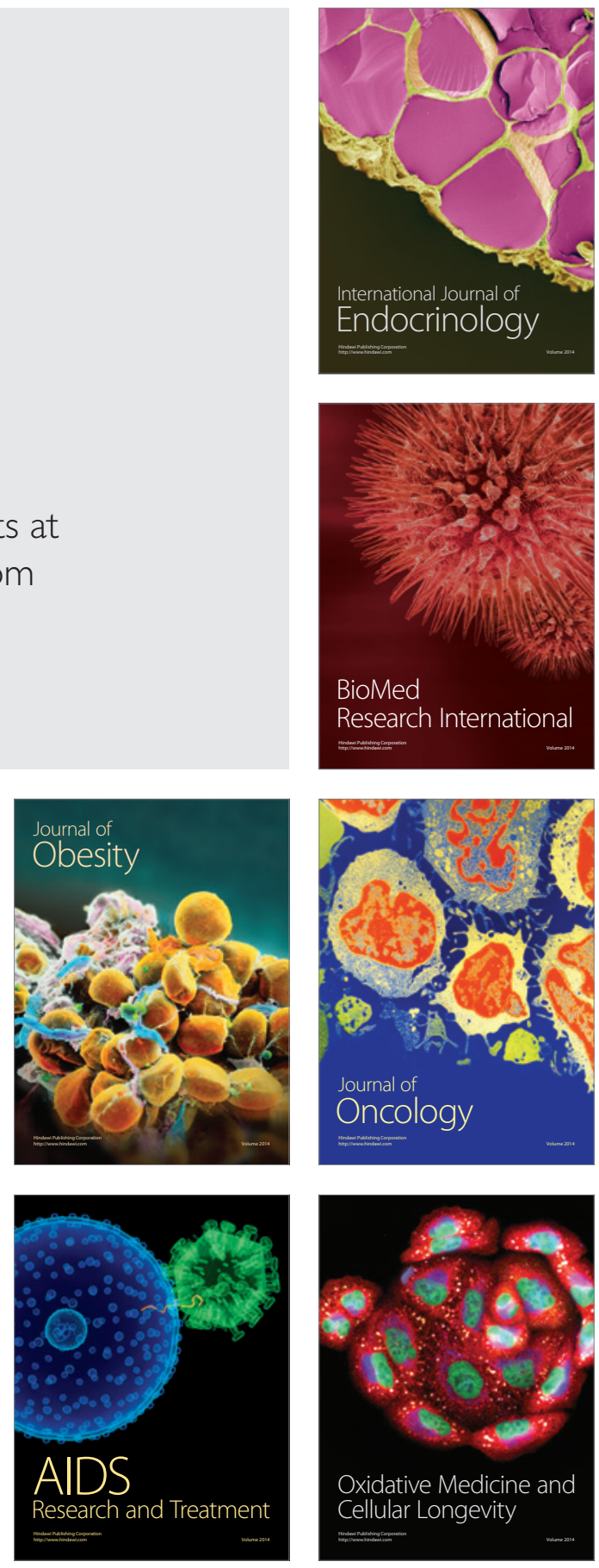